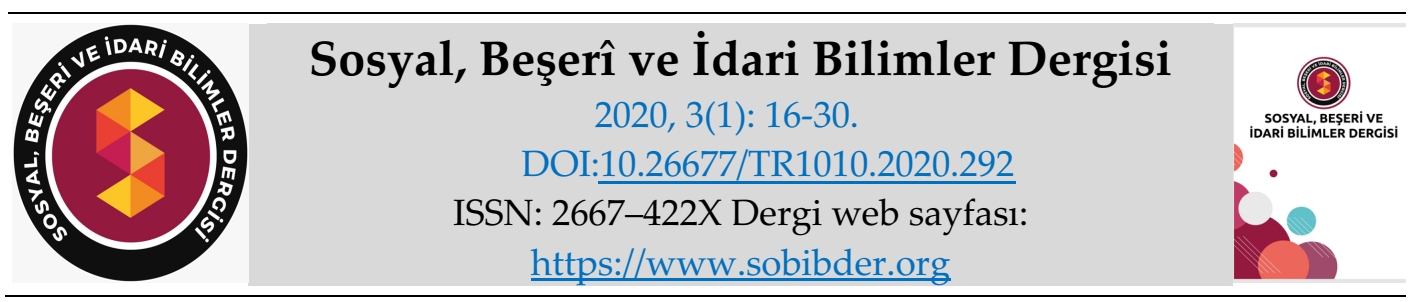

ARAȘTIRMA MAKALESİ

\title{
Akhisar İlçesinde (Manisa) Adlarını Bitki Örtüsünden Alan Coğrafi Ögeler*
}

Dr. Öğr. Üyesi Ferdi AKBAŞ, Osmaniye Korkut Ata Üniversitesi, Kadirli Sosyal ve Beşeri Bilimler Fakültesi, Osmaniye, e-posta: ferdi.akbas45@gmail.com

ORCID: https://orcid.org/0000-0003-1899-1458

Özcan AKINLI, Erzurum Valiliği, Özel Kalem Müdürlüğü, Açık Kapı Koordinatörlüğü, Erzurum, e-posta: 45ozcanakinli@gmail.com ORCID: https://orcid.org/0000-0001-6426-6316

Öz

Yeradları bir coğrafi mekanın adeta kimliği niteliğindedir. Bir yerleşim biriminin kurulduğu günden bu yana başından geçen tarihi süreçler hakkında bilgi veren yer adları günümüzde yerleşmelerin sosyokültürel ve sosyo-ekonomik geçmişlerinin aydınlatılmasını sağlamaktadır. Bu araştırma da aslında bir nevi bu amaca hizmet etmektedir. Sahip olduğu coğrafi konumunun etkisiyle günümüze gelinceye kadar birçok medeniyete ev sahipliği yapmış olan Akhisar'da coğrafi birimlerin adlandırılmasında etkili olan faktörlerden birini oluşturan bitki örtüsünün söz konusu çalışma ile yeradı verilmesinde ne kadar etkili olduğu ilçedeki coğrafi birimlerinin adlarının elde edilen kaynaklar vasıtasıyla tek tek ve detaylı bir şekilde analiz edilmesiyle ortaya çıkarılmaya çalışılmıştır. Ege Bölgesi'nin Asıl Ege Bölümü sınırları dahilinde yer alan araştırma sahası idari bakımdan Manisa iline bağlıdır. Manisa ilinin gelişmiş ilçelerinden biri olan Akhisar İstanbul-Balıkesir karayolu üzerinde yer almaktadır. Coğrafi konum, iklim özellikleri, ulaşım koşulları gibi etkenler neticesinde sahanın nüfusu günümüz itibariyle 170.000 'i aşmıştır. Tarihi dönemlerde de coğrafi açıdan benzer derecede önem taşıyan ilçede birtakım coğrafi ögelerin adlandırılmasında bitki örtüsünden faydalanılmıştır. Bitki örtüsünden adlarını alan coğrafi ögelerin tespit edilmesinde 1 / 25000 ölçekli Akhisar paftasından istifade edilmiştir. Söz konusu unsurların tespit edilme sürecinden sonra literatür tarama aşaması başlamış ve bu dönemde Akhisar'ın yer adları ile ilgili yapılmış olan tüm çalışmalara ulaşılmaya çalışılmışıı. Son aşama ise arazi gözlemleri ve mülakatlardan oluşmaktadır. İlgili yer adlarının yerinde ve doğru bir şekilde değerlendirilebilmesi için yer aldıkları yerleşim birimlerinin tamamına gidilerek buradaki yerel halkla mülakatlar gerçekleştirilmiştir. Yerel halkın yanında ilçenin tarihi geçmişi ve coğrafi yapısı hakkında bilgi sahibi olan yerel araştırmacıların bilgi birikimlerinden de faydalanılmıştır. Tüm bunlar neticesinde elde edilen veriler çeşitli sınıflara ayırılarak gözden kaçması mümkün olabilecek noktalar minimuma indirilmiştir.

* Bu çalışma Özcan Akınlı tarafından tamamlanan yüksek lisans tezinden üretilmiştir.

Anahtar Kelimeler: Yer Adları, Coğrafi Mekan, Bitki Örtüsü, Akhisar.

Makale Gönderme Tarihi: 12.10.2019

Makale Kabul Tarihi: 17.01.2020

Önerilen Atıf:

Akbaş, F. ve Akınlı, Ö. (2020). Akhisar İlçesinde (Manisa) Adlarını Bitki Örtüsünden Alan Coğrafi Ögeler, Sosyal, Beşeri ve İdari Bilimler Dergisi, 3(1): 16-30.

(C) 2020 Sosyal, Beşerî ve İdari Bilimler Dergisi. 


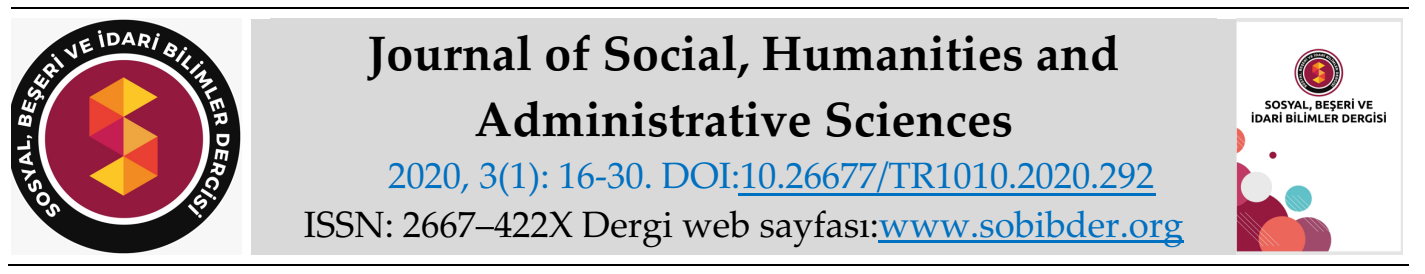

$\underline{\text { RESEARCH PAPER }}$

\title{
Geographical Elements Named After Vegetation in Akhisar District (Manisa)
}

Assistant Professor Dr. Ferdi AKBAŞ, Osmaniye Korkut Ata University, Kadirli Faculty of Social Sciences and Humanities, Osmaniye, e-mail: ferdi.akbas45@gmail.com

ORCID: https://orcid.org/0000-0003-1899-1458

Özcan AKINLI, Governorship of Erzurum, Open Door Coordinator, Erzurum, e-mail: 45ozcanakinli@gmail.com

ORCID: https://orcid.org/0000-0001-6426-6316

\begin{abstract}
Places are almost the identity of a geographical place. Place names that provide information about the historical processes that have been going on since the establishment of a settlement provide an explanation of the socio-cultural and socio-economic histories of the settlements today. This research actually serves this purpose. In Akhisar, which hosted many civilizations until the present day the influence of geographical location and geographical units of vegetation that constitutes one of the factors influential in the naming of the name of the place in question with the work, how effective is the provision in the county through individual and geographic sources, the names of the units obtained by a detailed analysis was tried to be uncovered. The research area within the borders of the main Aegean Division of the Aegean region is administratively dependent on the province of Manisa. Akhisar, one of the developed districts of Manisa province, is located on the Istanbul-Balıkesir Highway. As a result of factors such as geographical location, climate characteristics, transportation conditions, the population of the site has exceeded 170,000 as of today. In historical periods, vegetation was used in naming some geographical elements in the district which was of similar importance in terms of geography. The geographical elements named after the vegetation were used to determine the 1 / 25000 scale Akhisar paftasinın. After the process of identifying these elements, the literature search phase started and during this period, all studies about the place names of Akhisar were tried to be reached. The final stage consists of field observations and interviews. In order to evaluate the names of the places in place correctly, we visited all the settlements and conducted interviews with the local people. In addition to the local people, the knowledge of local researchers who have knowledge of the historical history and geographical structure of the district has also been made available. As a result of all these, the data obtained is divided into various classes and the points that may be overlooked are minimized.
\end{abstract}

Keywords: Place Names, Geographical Location, Vegetation, Akhisar.

Received: 12.10 .2019

Accepted: 17.01 .2020

\section{Suggested Citation:}

Akbaş, F. and Akınlı, Ö. (2020). Geographical Elements Named After Vegetation in Akhisar District (Manisa), Journal of Social, Humanities and Administrative Sciences, 3(1): 16-30.

(C) 2020 Sosyal, Beşerî ve İdari Bilimler Dergisi. 


\section{Gíriş}

Bu çalışma 1/25000 ölçekli Akhisar topografya haritasında geçen bitki örtüsü kaynaklı coğrafi ögelerin tespit edilmesi amacıyla yapılmıştır. Çalışma yapılırken ilk olarak Akhisar Zeynelzâde Halk Kütüphanesi, Manisa Halk Kütüphanesi, Türk Tarih Kurumu, Afyonkarahisar Gedik Ahmet Paşa Halk Kütüphanesi ve Afyon Kocatepe Üniversitesi kütüphanelerinden istifade edilmiştir. İlerleyen süreçte elde edilen yazılı kaynakların analiz edilmesinden sonra hakkında veri bulunmayan coğrafi ögelerle ilgili olarak onların bulunduğu yerleşim biriminde yer alan muhtarlarla mülakat yapılmıştır. Çalışma yapılırken bitki örtüsünden adını alan coğrafi ögelerin bulunduğu yerleşmelerin tamamına gidilerek yerel halk ile görüşmeler yapılmıştır. Bunun yanında yörenin yerel tarihini araştıran, köy köy dolaşıp derlemeler yapmış ve çevreyi iyi tanıyan yerel tarih araştırmacısı öğretmen Mustafa Kuzucuk'un bilgilerinden de istifade edilmiştir.

\section{ADLARINI BITKI ÖRTÜSÜNDEN ALAN COĞRAFI ÖGELER}

Fitotoponim: Ağaç ve bitkilerin adlarından oluşan yeradına denir (Yavuz ve Şenel, 2013: 2245). Bu bölümde adlarını ağaçlardan alan coğrafi ögeler, adlarını makilerden alan coğrafi ögeler, adlarını ziraî bitkilerden alan coğrafi ögeler ile adlarını süs bitkilerinden alan coğrafi ögeler bulunmaktadır. Söz konusu başlıklar detaylı bir şekilde açıklanmış olup, bazı coğrafi ögelerin 1/25.000'lik Akhisar topografya haritasının hangi paftasında yer aldığ verilmiştir.

\section{Adlarını Ağaçlardan Alan Coğrafi Ögeler}

Ahlat Deresi < ahlat dere+si. Ahlat, "beyaz çiçekli, dikenli veya dikensiz bir ağaççıtır" (Baytop, 2007: 23).

Ahlat Sırtı < ahlat sırt+1. Ahlat için bk. Ahlat Deresi.

Akçam Tepesi < ak çam tepe+si.

Akkavak Deresi < ak kavak dere+si.

Alaçam Tepesi $<$ ala çam tepe+si.

Ardıçlı Dere < ardıç+lı dere. Ardıç, kışın yapraklarını dökmeyen, bazı türlerinin meyveleri tedavi amacıyla kullanılan bazı türlerinden de katran elde edilen ağaçlardır (Baytop, 2007: 33).

Ardıçlı Tepe (3) (J20D1, J20D4, K20A1) < ardıç+lı tepe. Ardıç için bk. Ardıçlı Dere.

Büyükdavulga Tepesi < büyük davulga tepe+si. Davulga için bk. Davulga Deresi.

Çakalçam Sırtı < çakal çam sırt+1.

Çam Pınarı < çam pınar+1.

Çam Sırtı < çam sırt+1.

Çam Tepesi < çam tepe+si.

Çamlar Sırtı < çam+lar sırt+1.

Çamlı Dere < çam+lı dere.

Çamlı Tepe (6) (J19D3, J20D4, K19A1, K19A2, K19B2, K19B3) < çam+lı tepe.

Çamlıca Tepesi $<$ çam $+l_{1}+$ ca tepe+si.

Çamlık Deresi < çam+lık dere+si. 
Çamlık Sırtı < çam+lık sırt+1.

Çamtarla < çam tarla.

Çardakçam Sırtı < çardak çam sırt+1.

Çetlemik Tepesi < çetlemik tepe+si. Çetlemik için bk. Çitlembik Tepesi.

Çetlemikli Dere < çetlemik+li dere. Çetlemik için bk. Çitlembik Tepesi.

Çınar Çeşmesi < çınar çeşme+si.

Çınar Deresi $<$ çınar dere+si.

Çınar Tepesi < çınar tepe+si.

Çınarcık Deresi < çınar+cık dere+si.

Çınarcık Sırtı < çınar+cık sırt+1.

Çınarlı Çeşme < çınar+lı çeşme.

Çınarlı Dere (2) $($ K19B2, K20A1) < çınar+lı dere.

Çınarlı Pınar < çınar+lı pınar.

Çınarlı Tepe < çınar+lı tepe.

Çitlembik Tepesi < çitlembik tepe+si. Çitlembik, "kışın yapraklarını döken bazı türlerinin meyvesi yenen ağaççıklardır" (Baytop, 2007: 74). Baytop (2007: 74), çitlembiğin diğer adlarının çitlenbik, çitemek, çitemik, çitlenbek olduğunu belirtmektedir. Yöre halkınca çetlemik olarak da bilinmektedir. Yöre halkı bu tepede asırlık bir çitlembik ağacı olduğunu ve tepenin adını bu ağaçtan aldığını söylemektedir.

Çitlenbik Tepesi < çitlenbik tepe+si. Çitlenbik için bk. Çitlembik Tepesi.

Çitlenbiktarla < çitlenbik tarla. Çitlenbik için bk. Çitlembik Tepesi.

Çöğürlü Tarla < çöğür+lü tarla. Baytop (2007: 77), bitkinin diğer adının çördük olduğunu ve çördük'ün "20-50 cm yükseklikte, iki veya çok yıllık, sarı çiçekli ve kuvvetli kokulu bir bitki" olduğunu belirtmektedir. Çöğür yörede ve Derleme Sözlügü̈'nde "dikenli ağaç" anlamındadır (DS, 1968: 1280).

Çöğürlü Tepe < çöğür+lü tepe. Çöğür için bk. Çögürlü Tarla.

Çögürlük Mevki(s)i < çöğür+lük mevki+(s)i. Çöğür için bk. Çöğürlü Tarla. Mevki, yörede Çögürlüyurt adıyla bilinmekte olup, mevkide çöğürlerin çok olması nedeniyle mevki bu adı almiştır.

Davulga Deresi < davulga dere+si. Davulga kelimesi Derleme Sözlüğü'nde Manisa ve çevresi ile Bursa ve Kütahya' da "kırmızı kabuklu sert ve dayanıklı bir ağaç" anlamındadır (DS, 1969: 1382). Davulga; İzmir, Balıkesir, Çanakkale, Bursa ve Edirne'de davulgu adıyla "kocayemiş ağacı ve meyvesi" olarak bilinmektedir (DS, 1969: 1382). Davulga, bitki adları sözlüğünde de "kocayemiş" olarak yer almaktadır (Baytop, 2007: 85). Yöre halkınca davulga, gövdesi ve kabuğu kırmızımsı bir ağaç olarak bilinmektedir. Davulga Deresi de davulga ağaçlarının dere kenarında sıkça yer alması nedeniyle bu adı almıştır.

Davulga Sırtı < davulga sırt+1. Davulga için bk. Davulga Deresi.

Davulgalı Dere $<$ davulga $+l_{1}$ dere. Davulga için bk. Davulga Deresi. 
Davulgalı Tepe < davulga+lı tepe. Davulga için bk. Davulga Deresi.

Döngel Deresi < döngel dere+si. Döngel için bk. Döngel Sırtı.

Döngel Sırtı < döngel sırt+1. Döngel, “2-3 m. yükseklikte, çalı görünüşünde, dikenli ve beyaz çiçekli bir ağaççıktır" (Baytop, 2007: 94). Yöre halkı bu sırtta döngel ağaçlarının çok olması nedeniyle sırtın bu adı aldığını söylemektedir.

Düzçam Tepesi < düz çam tepe+si.

Gökçam Tepesi < gök çam tepe+si.

Haydarçam Sırtı < haydar çam sırt+1.

Işılkavak Deresi < 1ş1 kavak dere+si.

İkiçam Tepesi < iki çam tepe+si.

Kabaağaç Kıranı < kaba+ağaç kıran+1. Kabaağaç için bk. Kabaçtarla.

Kabaağaç Sırtı < kaba+ağaç sırt+1. Kabaağaç için bk. Kabaçtarla.

Kabaçtarla < kabaç tarla. Yöre halkı Pelitli Meşe ağacını Kabaağaç ya da Kabaç adıyla bilmektedir. Geçmiş dönemlerde bu tarla kenarlarında bu ağaçların çok olması nedeniyle tarla Kabaçtarla adını almıştır. Kabaç kelimesi Derleme Sözlügü̈'nde de "kalın gövdeli meşe ağacı" ve "büyük ağaç" anlamlarındadır (DS, 1969: 2577).

Kanlıkırağaç Düzü < kan+lı kır ağaç düz+ü.

Karaçam Sırtı < kara çam sırt+1.

Karadavulga Tepesi (2) (J19C3, K20A1) < kara davulga tepe+si. Davulga için bk. Davulga Deresi.

Karadavulgalı Tepe $<$ kara davulga + lı tepe. Davulga için bk. Davulga Deresi.

Karadavulgalık Sırtı $<$ kara davulga + lık sırt +1 . Davulga için bk. Davulga Deresi.

Karakabaağaç Sırtı < kara kaba+ağaç sırt+1. Kabaağaç için bk. Kabaçtarla.

Karakabaç Deresi < kara kabaç dere+si. Kabaç için bk. Kabaçtarla.

Karakabaç Mevki(s)i < kara kabaç mevki+(s)i. Kabaç için bk. Kabaçtarla.

Karamançam Sırtı < karaman+çam sırt+1.

Kavaklı Çeşme < kavak+lı çeşme.

Kavaklı Dere (3) (J19C4, J20D3, K19A2) < kavak+lı dere.

Kavaklı Sırt $<$ kavak+lı sırt.

Kılıççam Tepesi < kılıç çam tepe+si.

Kocaçam Sırtı < koca çam sırt+1.

Kocaçam Tepesi $<$ koca çam tepe+si.

Kocadavulga Sırtı < koca davulga sırt+1. Davulga için bk. Davulga Deresi.

Koru Dağ $1<$ koru dağ+1. Yöre halkının verdiği bilgiye göre dağ, meşe korusuyla kaplı olduğu için bu adı almıştır.

Koruca Tepe $<$ koru+ca tepe.

Kuzukabaağaç Tepesi < kuzu kaba+ağaç tepe+si. Kabaağaç için bk. Kabaçtarla. 
Meşeli Tepe (2) $(\mathrm{K} 19 \mathrm{~B} 4, \mathrm{~K} 20 \mathrm{~A} 1)$ < meşe+li tepe.

Musaçam Tepesi < Musa çam tepe+si. Yöre halkının verdiği bilgiye göre tepe, Musa adlı bir şahsın diktiği ve yörede Musanın Çamı adıyla bilinen çam ağacından adını almıştır.

Mutlu Sırtı < mutlu sırt+1. Sırt, yörede Murtluk Sırtı adıyla bilinmektedir. Yöre halkı, yörede Murt adı verilen bir ağaç türünün bu sırtta çok yetişmesi nedeniyle sırtın bu adı aldığını söylemektedir.

Palamutlu Burun < palamut+lu burun. Palamut, "meşe türlerinin meyvesine verilen genel addır. Çiğ olarak veya külde pişirildikten sonra yenir veya hayvan yemi olarak kullanılır" (Baytop, 2007: 221).

Palamutlu Tepe $<$ palamut+lu tepe. Palamut için bk. Palamutlu Burun.

Pıynarlı Dere < pıynar+lı dere. Pıynar kelimesi Derleme Sözlügü̈nde Afyonkarahisar, Isparta, Denizli ve Manisa'da "meşe çalısı" anlamındadır (DS, 1977: 3451). Bitki, Türkçe Bitki Adları Sözlügü̈nde Pırnar Meşesi adı ile geçmektedir (Baytop, 2007: 226).

Pıynarlı Tepe < pıynar+lı tepe. Pıynar için bk. Pıynarlı Dere.

Sarıdavulga Sırtı < sarı davulga sırt+1. Davulga için bk. Davulga Deresi.

Selvili Köyü < selvi+li köy+ü. Yöreden ve Mustafa Kuzucuk'tan alınan bilgiye göre köy halkının ilk yerleşim yeri Saruhanlı ilçesinin Boğazhan Mevkisi olup zamanla bu mevkinin hayvancılık yapmak için elverişli olmaması nedeniyle köy halkı bugünkü yerleşim yerine göç etmiştir. Köy halkı, köyün arazisini Kırkağaç'a bağlı Bakır kasabasında yaşayan iki kardeşten satın almış ve buraya yerleşmiştir. Köy, 1951 yılına kadar Çobanhasan köyüne bağlı Selvili adıyla bir mahalle iken 1951'de bağımsız bir köy haline gelmiştir (Resmî Gazete, 2 Ocak 1951: 325). Köyün bulunduğu alanda selvi ağaçlarının çok olması sebebiyle köye Selvili adının verildiği yöre halkınca ifade edilmektedir.

Serpikçam Sırtı < serpik çam sırt+1.

Sirnekli Sırtı < sirnek+li sırt+1. Yöre halkı eski dönemlerde hayvanların ahırlarını temizlemek için kullanılan çalı süpürgesinin yapıldığı ve yörede sirnek adıyla bilinen bir ağacın bu sırtta çok olması nedeniyle sırtın bu ağaçtan adını aldığını söylemektedir.

Solakoğluçam Tepesi < solak oğ(u)l+u çam tepe+si.

Söğütcük Deresi < söğüt+cük dere+si.

Söğütcük Tepesi < sögüt+cük tepe+si.

Söğütlü Alan < söğüt+lü alan.

Söğütlü Çeşme < söğüt+lü çeşme. Yöreden alınan bilgiye göre çeşme, çeşmenin başındaki dört söğüt ağacından adını almıştır.

Söğütlü Dere < söğüt+lü dere.

Söğütlü Köyü < söğüt+lü köy+ü. Osmanlı dönemi arşiv belgelerinde Söğüd, Söğüdlü (Söğüdlüoğulları) adlarıyla Kütahya, Meraş, Hamîdeli, Karahisâr-1 Şarkî, Biga, Canik, Hudâvendigâr, Karasi, Ankara sancakları ve Diyarbekir eyâletinde konar-göçer Yörükân taifesinden bir cemaat bulunmaktadır (Türkay, 1979: 682). Yine 16. yüzyıl tapu tahrir defterinde Sögüdlü adıyla Beğdili Boyu'na mensup olarak Biga sancağında bir cemaat bulunmaktadır (Halaçoğlu, 2011: 2048). Ancak bu cemaatlerin dışında yöreden alınan bilgiye göre köyün güneyinden geçen Akhisar-Sındırgı-Simav yolunun alt tarafındaki çay yatağında eskiden söğüt ve çınar ağaçlarının çok olması nedeniyle köy Söğütlü adını almıştır. 
Söğütlü Pınar < söğüt+lü pınar.

Söğütlü Sirt < söğüt+lü sirt.

Tallı Tepe < tal+lı tepe. Tal kelimesi Derleme Sözlüğü'nde Konya'da "ardıç", İstanbul'da (Türkistan göçmenleri arasında) "sögüut" anlamındadır (DS, 1969: 3812). Yörede tal, bazı köylerde ağaç, bazı köylerde ağacın dalı olarak bilinmektedir.

Tekçam Mevki(s)i < tek çam mevki+(s)i.

Tekelçam Tepesi < tekel çam tepe+si.

Tellikavak Sırtı < tel+li kavak sırt+1. Ballıca beldesi yakınında yer alan sırt, yörede Tellikavak adıyla bilinen yapraklarının bir tarafının koyu yeşil, diğer tarafının altın sarısı bir renginin olduğu bir kavak cinsinin bu sırtta çok yetişmesinden dolayı sırtın bu adı aldığı yöre halkınca belirtilmektedir.

Topakçam Tepesi < topak çam tepe+si.

Üçağaç Tepesi < üç ağaç tepe+si.

Yarıçam Sırtı < yarı çam sırt+1.

Yelekçam Sırtı < yelek çam sırt+1.

Yelekçam Tepesi < yelek çam tepe+si.

Yılanlıçam Tepesi < yılan+lı çam tepe+si.

\section{Adlarını Makilerden Alan Coğrafi Ögeler}

Akçalı Deresi < ak çalı dere+si.

Çalı Tepesi (3) (K19A1, K19B3, K19B3) < çalı tepe+si.

Çalılı Tepe (2) (K19A2, K19B2) < çalı+lı tepe.

Çalılık Sırt < çalı+lık sırt.

Çalılık Tepe $<$ çalı+lık tepe.

Çaltı Tepesi < çaltı tepe+si.

Çaltıboğaz < çaltı boğaz. Boğaz için bk. Boğaz Tepe. Yöre halkınca Çaltılıboğaz adıyla bilinmektedir.

Çetili Sırt < çeti+li sırt. Çeti kelimesi Derleme Sözlüğü'nde Şanlıurfa, Kilis, İçel, Antalya ve Muğla'da "baklagillerden taneleri hayvanlara verilen, çalısından süpürge yapılan dikenli bir çalı" anlamındadır (DS, 1968: 1150). Türkçe Bitki Adları Sözlügü̈nde çeti, 30-100 cm yükseklikte, dikenli ve sarı çiçekli bir çalıdır (Baytop, 2007: 69).

Çetili Tepe < çeti+li tepe. Çeti için bk. Çetili Sırt.

Çubukçalı Tepesi < çubuk çalı tepe+si.

Gengerli Çeşme < genger+li çeşme. Baytop (2007: 115), bitkinin diğer adının gengel olduğunu ifade etmekte ve gengel'i “30-100 cm yükseklikte, iki yıllık, mor çiçekli, otsu bir bitki” olarak tarif etmektedir. Genger kelimesi Derleme Sözlügü̈nde ise Burdur, Edirne, Kırklareli, İzmir ve Balıkesir' de "ilkbaharda yetişen bir ya da iki metre boyunda olan, gövde özü yenilen, dikenli bir çeşit bitki, deve dikeni, eşek dikeni" anlamındadır (DS, 1969: 1991). Yöre halkından edinilen 
bilgiye göre çeşmenin suyunun akıp taştığı alanda genger dikenlerinin bolca olması nedeniyle çeşmeye bu ad verilmiştir.

Geven Deresi < geven dere+si. Geven, "çok yıllık dikenli ve yastık biçimindeki dağ bitkileridir. Bazı türlerinin gövdelerinden kitre denilen zamk elde edilir. Dikenleri yakıldıktan sonra hayvan yemi olarak kullanılır" (Baytop, 2007: 115-116). Baytop (2007: 116), bitkinin diğer adlarının çekme, gön, kavan, ketire, kerte ve keven olduğunu belitmektedir.

Gevenli Tepe < geven+li tepe. Geven için bk. Geven Deresi.

Hayıtlı Dere (3) (K19B3, K19B3, K20A1) < hayıt+lı dere. Hayıt, "1-3 m. yükseklikte, çalı görünüşünde, soluk pembe veya mavi çiçekli bir bitkidir. Kökleri iplik boyamakta kullanılır" (Baytop, 2007: 132). Yöreden edinilen bilgiye göre dere kenarında hayıtların çok olması nedeniyle dere adını hayıtlrdan almıştır.

Karaağaç < kara ağaç. Karaağaç için bk. Karaağaç Deresi.

Karaağaç Deresi < kara ağaç dere+si. Yöreden edinilen bilgiye göre Karaağaç olarak adlandırılan çalılı bir bitki türünün dere yatağında çok görülmesinden dolayı dere bu adı almıştır.

Karaağaç Mevki(s)i < kara ağaç mevki+(s)i. Karaağaç için bk. Karaağaç Deresi.

Karaağaç Sırtı (2) (J19C3, K19A2) < kara ağaç sırt+1. Karaağaç için bk. Karaağaç Deresi.

Karaçaltı Mevki(s)i < kara çaltı mevki+(s)i. Yöre halkından alınan bilgiye göre mevkinin eskiden çaltılık bir alan olması nedeniyle mevki bu adı almıştır.

Karahayıt Mevki(s)i < kara hayıt mevki+(s)i. Hayıt için bk. Hayıtlı Dere.

Kelçalı Tepesi < kel çalı tepe+si. Tepe yörede Çalı Tepesi olarak bilinmektedir.

Keven Tepeleri < keven tepe+ler+i. Keven için bk. Geven Deresi.

Koruçalı Tepesi $<$ koru çalı tepe+si.

Kürgaranti Sırtı < kür garanti sırt+1. Kür, "bögürtlen” anlamındadır (DS, 1975: 3042; Baytop, 2007: 194). Yörede de böğürtlene kür üzümü adı verilmektedir. Ayrıca yöre halkı, böğürtlenin yetiştiği dikenli bitkiye de garantı ya da kür adını vermektedir.

Mersin Tepesi (2) $(J 19 C 2$, K19B3) < mersin tepe+si. Mersin, “5 m. kadar yükselebilen, kışın yapraklarını dökmeyen, beyaz çiçekli bir ağaççıktır" (Baytop, 2007: 206).

Mersinli Dere $<$ mersin+li dere. Mersin için bk. Mersin Tepesi.

Mersinli Sırt < mersin+li sırt. Mersin için bk. Mersin Tepesi.

Mersinli Tepe (2) (J19C3, K19B1) < mersin+li tepe. Mersin için bk. Mersin Tepesi.

Safran Tepesi < safran tepe+si. Safran, "20 cm. kadar yükseklikte, sonbaharda mor renkli ve büyük çiçekler açan, yumrulu bir bitkidir. Koku verici ve boyar madde olarak kullanılmaktadır" (Baytop, 2007: 232). Yöre halkı safran bitkisinin bu tepede çok olması nedeniyle tepeye bu ad verildiğini söylemektedir.

Sakızcı Deresi < sakız+cı dere+si. Sakız Ağacı, "1-5 m. yükseklikte, kışın yapraklarını dökmeyen, Ege ve Akdeniz bölgelerinde yaygın olarak yetişen, meyvelerine çıtımık adı verilen ve meyveleri çiğ olarak tüketilen dallarından damla sakızı elde edilen bir ağaççıktır" (Baytop, 2007: 233).

Sarıçalı Köyü < sarı çalı köy+ü. Osmanlı dönemi arşiv belgelerinde Sıracalı adıyla Aydın sancağı ile Saruhan sancağı Mağnisa kazâsında bir aşiret bulunmaktadır (Türkay, 1979: 129). Ancak bu 
aşiretin ötesinde yöre halkından alınan bilgiye göre köy, geçmişte şimdiki yerinin üst kısmındaki çalılarla kaplı tepede kurulmuş ve çalıların yoğun olduğu bu köye Sarıçalı adı verilmiştir.

Somaklı Sırt < somak+lı sırt. Somak, "1-3 m. yükseklikte, genç dalları kırmızımtırak tüylü, birleşik yapraklı, çalı görünüşünde bir ağaççıktır. Olgun meyveleri somak ekşisi adı altında baharat olarak kullanılır" (Baytop, 2007: 249-250).

Somaklı Tepe (J19D4) < somak+lı tepe. Somak için bk. Somaklı Sırt.

Somaklı Tepe (J20D4) < somak+lı tepe. Somak için bk. Somaklı Sırt.

Somaklı Tepe (K19B2) < somak+lı tepe. Somak için bk. Somaklı Sırt.

Tütenli Köyü < tüten+li köy+ü. Yöreden ve Kuzucuk'tan alınan bilgiye göre eski adı Milinge olan köy, eskiden Rum halkının yerleşim yeridir. Rumca olan Milinge adı, köyde tütün yetiştiriciliğinin meşhur olması nedeniyle kaymakamlık kararıyla Tütenli olarak değiştirilmiştir. Köy, Aydın Vilâyet Sâlnâmesi'nde (R.1307/H.1308) Körük nahiyesine bağlı 277 nüfuslu Milenge karyesi adıyla geçmektedir (Câvid, 2010: 448).

Zeytinçalı Tepesi < zeytin çalı tepe+si.

Ayrık Sırtı < ayrık sırt+1. Yöre halkından edinilen bilgiye göre Ayrık Sırtı "ayrık otunun çokça bulunduğu sırt" anlamındadır. Ayrık otu, "çok yıllık, otsu bir bitkidir" (Baytop, 2007: 39).

Ayrık Tepesi < ayrık tepe+si. Ayrık için bk. Ayrık Sırtı.

Baklalık Kırı < bakla+lık kır+1. Kır için bk. Kır Tepe. Yöre halkı bu kırda acı bakla olarak bilinen yabani baklaların çok olduğunu ve kırın adını bu baklalardan aldığını söylemektedir.

Ballık Deresi (3) (J19C3, K20A1, J20D4) < ballık dere+si. Ballık kelimesi yörede bazı köylerde Ballık Otu, bazı köylerde de Bollık Otu olarak bilinmektedir. Bollık kelimesi Derleme Sözlüğü'nde “baklagillerden çiçeği emildiğinde tatlımsı bir madde çıkaran bitki anlamındadır (DS, 1969: 735). Yöreden edinilen bilgiye göre Ballık Otu'nun dere kenarlarında ve tepelerde çokça olması nedeniyle dere bu adı almıştır.

Ballık Kırı < ballık kır+1. Ballık için bk. Ballık Deresi. Kır için bk. Kır Tepe.

Ballık Tepesi < ballık tepe+si. Ballık için bk. Ballık Deresi.

Boya Mevki(s)i < boya mevki+(s)i. Yöre halkının verdiği bilgiye göre Çamönü köyü yakınlarındaki bu mevkide köklerinden boya elde edilen bir çeşit boya otunun çok olması nedeniyle mevki bu adı almıştır.

Çayırlık Dere < çayır+lık dere. Çayır, "tabiî olarak veya ekilmek suretiyle ot yetişen yer ve bu yerde biten yeşil ot" anlamındadır (Doğan, 1981: 168). Yöre halkının verdiği bilgiye göre dere kenarlarında çayırlık alanların olmasından dolayı dere bu adı almıştır.

Çenger Deresi < çenger dere+si. Baytop (2007: 170), bitkinin diğer adının kenger olduğunu belirtmektedir. Kenger, "20-100 cm yükseklikte, dikenli, çok yıllık, sütlü ve otsu bir bitkidir".

Çimenli Çeşme < çimen+li çeşme.

Çömenli Dere < çömen+li dere. Çömen kelimesi Derleme Sözlüğü’nde Muğla Yerkesik'te "çimen", Denizli ile Muğla Hisarardı ve Düğrek'te "bostan bekçileri için yapılan koni şeklinde kulübe", Konya ve İçel'de "çakıl taşlarından yapılan yığın", Giresun'da "ot ve mısır saplarından yapılan küçük yığın" anlamındadır (DS, 1969: 1286). Çömen yöre halkınca "çimen" olarak bilinmektedir.

Çömenli Tepe < çömen+li tepe. Çömen için bk. Çömenli Dere. 
Emençayırı Mevki(s)i < emen çayır+1 mevki+(s)i. Emen için bk. Emen Tepesi. Çayır için bk. Çayırlık Dere.

Işkınlı Dere < 1şkın+lı dere. Işkın, Derleme Sözlüğü'nde "kayalık yerlerde ve dağlarda yetişen, yenilebilir bir çeşit ot" anlamındadır (DS, 1974: 2494).

Karaballık Deresi < kara ballık dere+si. Ballık için bk. Ballık Deresi.

Karaballık Mevki(s)i < kara ballık mevki+(s)i. Ballık için bk. Ballık Deresi.

Kevke Kışlağı < kevke kışlak+1. Kevke, "60 cm. kadar yükselebilen, çok yıllık, otsu ve sarı çiçekli bir bitkidir" (Baytop, 2007: 173). Kışlak için bk. Kışla Deresi.

Naneli Çeşme < nane+li çeşme. Yöre halkı çeşmenin suyundan içildiğinde sudan bir nane tadı alındığını bu nedenle de çeşmeye bu ad verildiğini söylemektedir.

Sarıtluk Deresi < sarı otluk dere+si.

Saz Deresi < saz dere+si. Saz Otu, "40-300 cm. yükseklikte, su kenarlarında yetişen, çok yıllık otsu bir bitkidir" (Baytop, 2007: 239).

Sazlı Dere < saz+lı dere. Saz için bk. Saz Deresi.

Sazlı Kır < saz+lı kır. Saz için bk. Saz Deresi. Kır için bk. Kır Tepe.

Sazoba Köyü < Saz oba köy+ü. Osmanlı dönemi arşiv belgelerinde Sazoba adıyla Saruhan sancağ 1 Akhisar kazâsı'nda Yörükân taifesinden bir cemaat bulunmaktadır (Türkay, 1979: 664). Ancak bu cemaatin dışında Kuzucuk, köy yakınından geçen Kumçayı kenarındaki sazlık araziden köyün adını aldığını, köyün önceki adının Sazlıoba olduğunu ifade etmektedir. Köy, Aydın Vilâyet Sâlnâmesi'nde (R.1307/H.1308) Gölmarmaracık nahiyesine bağlı Saz karyesi adıyla geçmektedir (Câvid, 2010: 449). Başbakanlık Osmanlı Arşivleri 16.yüzyıl tahrir defterlerinde ve Tapu-Kadastro Kuyûd-ı Kadîme Arşivi tahrir defterlerinde de köy, Palamud nahiyesine bağlı Saz adı ile geçmektedir (Emecen, 2013: 200).

\section{Adlarını Ziraî Bitkilerden Alan Coğrafi Ögeler}

\section{Adlarını Meyve Ağaçlarından Alan Coğrafi Ögeler}

Armutlu Çeşme < armut+lu çeşme.

Armutlu Yayla < armut+lu yayla

Asma Tepesi < asma tepe+si.

Asmalı Dere (2) (J19C3, K20A1) < asma+lı dere.

Ayvacık Sirtı < ayva+cık sirt+1.

Cevizli Tepe $<$ ceviz+li tepe.

Düzzeytin Sırtı < düz zeytin sırt+1.

Elmalık Tepe $<$ elma+lık tepe.

Erikli Dere (3) (J19C3, J20D4, K19B3) < erik+li dere.

Erikli Tepe $<$ erik+li tepe.

İğdecik Deresi $<$ iğde+cik dere+si.

İğdecik Tepesi < iğde+cik tepe+si. 
İğdeli Dere < iğde+li dere.

İğdeli Sırt < iğde+li sırt.

İğdeli Tepe < iğde+li tepe.

İğdelik Mevki(s)i < iğde+lik mevki+(s)i.

İncirlik Tepesi $<$ incir+lik tepe+si.

Kanlızeytin $<$ kan+ll zeytin.

Karadut Deresi $<$ kara dut dere+si.

Karadut Mevki(s)i < kara dut mevki+(s)i.

Karaincirlik Deresi < kara incir+lik dere+si.

Kestaneli Dere $<$ kestane+li dere.

Kirazlı Mevki < kiraz+lı mevki.

Limon Deresi $<$ limon dere+si.

Narlı Dere < nar+lı dere. Yöre halkı, dere kenarında nar ağaçlarının bulunması nedeniyle derenin adını nar ağaçlarından aldığını söylemektedir.

Payamlı Mevki < payam+lı mevki. Payam, yörede, Türkçe Bitki Adları Sözlüğü'nde ve Derleme Sözlüğü'nde "badem" anlamındadır (Baytop, 2007: 223; DS, 1969: 3414).

Payamlık Deresi < payam+lık dere+si. Payam için bk. Payamlı Mevki.

Sırayemişler Mevki(s)i < sıra yemiş+ler mevki+(s)i. Yemiş, yörede ve Derleme Sözlüğü'nde "incir" anlamindadır (DS, 1979: 4242).

Şeftalilik Sırtı < şeftali+lik sırt+1.

Yemişli Dere < yemiş+li dere. Yemiş için bk. Sırayemişler Mevki(s)i.

Zerdali Çeşmesi < zerdali çeşme+si. Çeşme, adını çeşmenin başında yer alan zerdali ağacından almiştır.

Zerdali Tepesi $<$ zerdali tepe + si.

Zeytin Sirtı < zeytin sirt+1.

Zeytin Tepesi < zeytin tepe+si.

Zeytinli Tepe (4) (K19A1, K19B3, K20A4, K20A1) < zeytin+li tepe.

Zeytinlik Kuyusu < zeytin+lik kuyu+su. Yöreden alınan bilgiye göre kuyu, adını yanında bulunan yaşlı bir zeytin ağacından almakta olup, kuyu yöre halkınca Zeytinli Kuyu adıyla bilinmektedir.

\section{Adlarını Sebzelerden Alan Coğrafi Ögeler}

Bakla Deresi < bakla dere+si.

Baklacık Tepesi < bakla+cık tepe+si.

Baklalı Çeşme < bakla+lı çeşme.

Baklalık Deresi < bakla+lık dere+si.

Kabak Deresi $<$ kabak dere+si. 
Kabak Tepesi (3) (K19B2, K20A1, K20A4) < kabak tepe+si.

Kabaklı Tepe $<$ kabak+lı tepe.

Karagöz Sırtı < karagöz sırt+1. Karagöz, Derleme Sözlüğü'nde "börülce" anlamındadır (DS, 1975: 2643).

Karagöz Tepesi (J20D4) < karagöz tepe+si. Karagöz için bk. Karagöz Sırtı.

Karakabak Sirtı < kara kabak sırt+1.

Sarımsak Kayası < sarımsak kaya+sı.

Soğan Sirtı < soğan sirt+1.

Soğanlı Tepe $<$ soğan+lı tepe.

\section{Adlarını Tahıllardan Alan Coğrafi Ögeler}

Arpalı Dere < arpa+lı dere.

Arpalı Tepe $<$ arpa+l1 tepe.

Buğdaylık Mevki(s)i < buğday+lık mevki+(s)i. Mevki, yöreden edinilen bilgiye göre Muştullar köyü halkının tarlalarının bulunduğu alan olup, bu tarlalara buğday ekimi yapılması nedeniyle mevki Buğdaylık Mevkisi adını almıştır.

Dereekin Mevki(s)i < dere ekin mevki+(s)i.

Susamlı Mevki < susam+lı mevki.

Mercimek Deresi $<$ mercimek dere+si.

Mercimek Tepesi < mercimek tepe+si.

Nohut Mevki(s)i $<$ nohut mevki+(s)i.

Nohut Tepesi (2) (J19C3, K19B4) < nohut tepe+si.

\section{Adlarını Süs Bitkilerinden Alan Coğrafi Ögeler}

Çiğdem Tepesi < çiğdem tepe+si. Çiğdem, "ilkbahar veya sonbaharda türlerine göre farklı renkte çiçek açan, çok yıllık, yumrulu bir bitkidir" (Baytop, 2007: 72). Çiğdem, Derleme Sözlüğü'nde (1968: 1206) Manisa Alaşehir'de "ay çiçeği" anlamındadır.

Lalelik Mevki(s)i < lale+lik mevki+(s)i.

Lalelik Tepesi $<$ lale+lik tepe+si.

Sümbüllü Deresi < sümbül+lü dere+si.

\section{SONUÇ}

Akhisar ilçesinde adlarını bitki örtüsünden alan coğrafi ögelerin tespit edilmesi amacını taşıyan bu çalışmada 1/25000 ölçekli Akhisar topografya haritasından faydalanılmıştır. Bitki örtüsünden kaynaklanan yeradlarının harita üzerinden belirlenmesiyle bunların gerçekliklerin araştırılması amacıyla uzun süren mülakatlar ve arazi gözlemleri yapılmıştır. Söz konusu çalışmada Akhisar'ın kırsal yerleşimlerini ve tarihi dokusunu iyi derecede bilen başta Mustafa Kuzucuk 
olmak üzere orta yaş üzerindeki insanlardan da istifade edilmiştir. Tüm bunlar Akhisar'da yer adı verme geleneğinin ortaya çıkarılması için yapılmıştır. Anadolu'nun sahip olduğu, dil zenginliğini ortaya çıkarmak ve gösterebilmek açısından önemli bir malzeme olan yeradları, geç kalınmadan tespit edilmeli ve bu alana gereken önem verilmelidir.

\section{KAYNAKLAR}

Ada, E. (2012). Eskişehir İli Yer Adları. (Yayınlanmamış Yüksek Lisans Tezi). Ege Üniversitesi, İzmir.

Akalın, Ş. H. (1997). Akhisar'da Karaca Ahmet Türbesi ve Bu Türbe ile İlgili İnançlar. 03.07.2014, http://turkoloji.cu.edu.tr/kisisel/akalin/KARACA HTM

Akdeniz, E. ve Şahin, M. K. (2014). Akhisar Gezi Rehberi. Akhisar: Akhisar Belediyesi Kültür Yayınları.

Algın, Y. ve Bozacı, G. B. (1999). Akhisar'ın Yerel Tarihi. Manisa: Emek Matbaacılık.

Alkayış, M. F. (2007). Türkiye Türkçesinde Bitki Adları. (Yayınlanmamış Doktora Tezi). Erciyes Üniversitesi, Kayseri.

Ayaz, B. (2006). Cumhuriyet'in Illk Yıllarında Akhisar Kazası (1923 - 1933). (Yayınlanmamış YL Tezi). Celal Bayar Üniversitesi, Manisa.

Banguoğlu, T. (2004). Türkçenin Grameri, Ankara: Türk Dil Kurumu Yayınları.

Baytop, T. (2007). Türkçe Bitki Adları Sözlügü̈, Ankara: Türk Dil Kurumu Yayınları.

Belce, A. (1968). Manisa İli Yer Adları. (Lisans Tezi). İstanbul Üniversitesi, İstanbul.

Bora, H. S. (1993). Allıance Israelite Universelle'in Osmanlı Yahudi Cemaatini Tarım Sektöründe Kalkındırma Çalışmaları ve İzmir Yakınlarında Kurulan Bir Çiftlik Okul: "Or Yehuda". Çağdaş Türkiye Tarihi Araştırmaları Dergisi, 1(3), 387 - 400.

Câvid, İ. (2010). Aydın Vilâyet Sâlnâmesi (R.1307/H.1308), Ankara: Türk Tarih Kurumu Yayınları.

Çetin, S. (2013). 64 No'lu Manisa Şer'iyye Sicili. (Yayınlanmamış YL Tezi). Celal Bayar Üniversitesi, Manisa.

Devellioğlu, F. (2006). Osmanlıca - Türkçe Ansiklopedik Lugat, Ankara: Aydın Kitabevi.

Dilçin, C. (1983). Yeni Tarama Sözlüğü, Ankara: Türk Dil Kurumu Yayınları.

Doğan, M. (1981). Büyük Türkçe Sözlük, Ankara: Birlik Yayınları.

Emecen, M. F. (2007). Tarih İçinde Manisa (İkinci Basım). Manisa: Manisa Belediyesi Kültür Yayınları.

Emecen, M. F.(2013). XVI. Asırda Manisa Kazâsı (2. Baskı). Ankara: Türk Tarih Kurumu Yayınları.

Eren, H. (2010). Yer Adlarımızın Dili, Ankara: Türk Dil Kurumu Yayınları.

Erkol, F. (2013). Afyonkarahisar İli Çay İlçesinin Mikrotoponimleri ve Dil İncelenmesi. (Yayınlanmamış YL Tezi). Afyon Kocatepe Üniversitesi, Afyonkarahisar.

Gökçen, İ. (1946). Saruhan'da Yürük ve Türkmenler, Manisa: Manisa Halkevi Yayınları.

Gökçen, İ. (1950). Tarihte Saruhan Köyleri, İstanbul: Berksoy Basımevi. 
Gülensoy, T. (2007). Türkiye Türkçesindeki Türkçe Sözcüklerin Köken Bilgisi Sözlüğü I-II, Ankara: Türk Dil Kurumu Yayınları.

Halaçoğlu, Y. (2011). Anadolu'da Aşiretler, Cemaatler, Oymaklar (1453 - 1650), İstanbul: Togan Yayıncılik.

http://tdkterim.gov.tr/bts/ (06.08.2014, 14.08.2014, 21.09.2014, 23.09.2014).

İzbırak, R. (1964). Coğrafya Terimleri Sözlüğü, Ankara: Doğuş Matbaacıllk ve Ticaret Limited Şirketi Matbaası.

İzdem, E. (1944). Dünkü-Bugünkü Akhisar, İstanbul: Ülkü Basımevi.

Kahraman, S. A. (2011). Günümüz Türkçesiyle Evliya Çelebi Seyahatnâmesi: Kütahya-Manisaİzmir-Antalya-Karaman-Adana-Halep-Şam-Kudüs-Mekke-Medine (1.Bask1). İstanbul: Yap1 Kredi Yayınları.

Karacan, N. (2014). Sinop İli Yerleşim Yeri Adları Üzerine Bir Dil İncelemesi. (Yayınlanmamış YL Tezi). Afyon Kocatepe Üniversitesi, Afyonkarahisar.

Karahan, L. (2013). Türkçede Söz Dizimi (19. Baskı). Ankara: Akçă̆ Yayınları.

Karakuyu, M., Sarıusta, F. ve Yalçın, S. (2012). Kentleşme Sürecinde Akhisar. Akhisar: Akhisar Belediyesi Kültür Yayınları.

Karakuyu, M. (2012). Mahalle Mahalle Akhisar, Akhisar: Akhisar Belediyesi Kültür Yayınları.

Karakuyu, M..(2012). Tarihi Coğrafyasıyla Akhisar, Akhisar: Akhisar Belediyesi Kültür Yayınları.

Korkmaz, Z. (2009). Türkiye Türkçesi Grameri Şekil Bilgisi, Ankara: Türk Dil Kurumu Yayınları.

Köylerimiz. (1968). Ankara: İçişleri Bakanlığı İller İdaresi Genel Müdürlüğü.

Kurgun, L. (2002). Denizli İli Yer Adları. (Yayınlanmamış Doktora Tezi). Pamukkale Üniversitesi, Denizli.

Müderrisoğlu, M. E. (1956). Akhisarlı Türk Büyükleri ve Eserleri, İzmir: Piyasa Matbaası.

Nagata, Y. (1979). 16. Yüzyılda Manisa Köyleri:1531 Tarihli Saruhan Sancağına Ait Bir Tahrir Defterini İnceleme Denemesi. Tarih Dergisi, Sayı 32, 731-758.

Nagata, Y. (1997). Tarihte Âyânlar Karaosmanoğulları Üzerinde Bir İnceleme, Ankara: Türk Tarih Kurumu Yayınları.

Özkılınç, A., Coşkun, A., Karazeybek, M., Sivridağ, A., Yüzbaşığlu, M. (1995). 166 Numaralı Muhâsebe-i Vilâyet-i Anadolu Defteri (937/1530), (Defter-i Hâkâni Dizisi: II). Ankara: Başbakanlık Devlet Arşivleri Genel Müdürlüğü.

Resmî Gazete, 11 Nisan 1989, Sayı 20136, s.3.

Resmî Gazete, , 16 Şubat 1945, Sayı 5933, s.8301.

Resmî Gazete, 2 Ocak 1951, Sayı 7697, s.325

Resmî Gazete, 21 Haziran 1934, Sayı 2733, s. 4003-4004.

Resmî Gazete, 27 Şubat 1947, Sayı 6543, s. 11937.

Satış, B. (1994). İlkçağdan Günümüze Akhisar, İzmir: Akhisar Sağlık Eğitim Kültür Vakfı Yayınları.

Sezen, T. (2006). Osmanlı Yer Adları (Alfabetik Sırayla), Ankara: Başbakanlık Devlet Arşivleri Genel Müdürlügü. 
Son Teşkilatı Mülkiyede Köylerimizin Adları. (1928). İstanbul: Hilâl Matbaası.

Şahin, İ. (2007). Türkçe Yer Adlarının Yapısı Üzerine. Türkiyat Araştırmaları Enstitüsü Dergisi, Sayı 32, 1-14.

Şahin, İ. (2011). Yeradı Bilim Çalışmalarında Mikrotoponiminin Yeri, Önemi ve Araştırma Yöntemi: Tırnak Köyü (İçel / Gülnar) Örneği. Turkısh Studies, 1807 - 1830.

Şahin, İ. (2013). Türkiye Yeradbiliminde Terim ve Tür Sınıflandırması Sorunları. Avrasya Terimler Dergisi, 1 (1), 46 - 58.

Şahin, İ..(2014). Toponimi Çalışmalarında Leksikosemantik Sınıflandırma Ne Şekilde Olmalıdır. 7. Uluslararası Dünya Dili Türkçe Sempozyumu, 16- 18 Ekim, Elazığ.

Şaşmaz, M. (2014). Türkiye'nin İdari Taksimatı (1920-2013), Ankara: Türk Tarih Kurumu Yayınları, XI.

Talaysüm, B. (1965). Akhisar İlçesi Monoğrafyası. (Lisans Tezi). İstanbul Üniversitesi, İstanbul.

Türkay, C. (2001). Başbakanlık Arşiv Belgelerine Göre Osmanlı İmparatorluğunda Oymak, Aşîret ve Cemaatlar, İstanbul: İşaret Yayınları.

Türkçe Sözlük. (2005). (10. Baskı). Ankara: Türk Dil Kurumu Yayınları.

Türkiye' de Halk Ağzından Derleme Sözlüğü. (1965, 1968, 1969, 1972, 1974, 1975, 1977, 1978, 1979). Ankara: Türk Dil Kurumu Yayınları, II-XI.

Umar, B. (1993). Türkiye'deki Tarihsel Adlar, İstanbul: İnkılâp Kitabevi.

Yavuz, S. ve Şenel, M. (2013). Yer Adları (Toponim) Terimleri Sözlüğü. Turkish Studies, 2239-2254. 